\title{
Cultural difference in emotions
}

\author{
Mohan Nitish
}

\section{INTRODUCTION}

Emotions:- Emotion in ordinary discourse, is any moderately short cognizant experience described by extreme mental movement and a high level of delight or dismay. Logical talk has floated to different implications and there is no agreement on a definition. Feeling is regularly interlaced with state of mind, demeanour, identity, air, and inspiration. In a few hypotheses, perception is an imperative part of feeling. Those acting basically on the feelings they are feeling may appear as though they are not considering, but rather mental procedures are as yet basic, especially in the understanding of occasions. For instance, the acknowledgment of our trusting that we are in a hazardous circumstance and the consequent excitement of our body's sensory system (quick pulse and breathing, sweating, muscle pressure) is necessary to the experience of our inclination apprehensive. Different hypotheses, be that as it may, guarantee that feeling is separate from and can go before comprehension.

Feelings are perplexing. As per a few speculations, they are a condition of feeling that outcomes in physical and mental changes that impact our conduct. The physiology of feeling is firmly connected to excitement of the sensory system with different states and qualities of excitement relating, clearly, to specific feelings. Feeling is additionally connected to behavioural propensity. Outgoing individuals will probably be social and express their feelings, while contemplative individuals will probably be all the more socially pulled back and cover their feelings. Feeling is regularly the main thrust behind inspiration, positive or negative. As per different hypotheses, feelings are not causal strengths but rather basically disorders of parts, which may incorporate inspiration, feeling, conduct, and physiological changes, yet nobody of these segments is the feeling. Nor is the feeling a substance that causes these parts.

Feelings include distinctive segments, for example, subjective experience, psychological procedures, expressive conduct, psychophysiological changes, and instrumental conduct. At one time, scholastics endeavoured to distinguish the feeling with one of the segments: William James with a subjective affair, behaviourists with instrumental conduct, psycho physiologists with physiological changes, et cetera. All the more as of late, feeling is said to comprise of the considerable number of segments. The distinctive segments of feeling are arranged fairly contrastingly relying upon the scholastic train. In brain research and logic, feeling normally incorporates a subjective, cognizant affair described basically by psychophysiological expressions, natural responses, and mental states. A comparative multicomponent portrayal of feeling is found in humanism. For instance, Peggy Thoits portrayed feelings as including physiological parts, social or enthusiastic marks (outrage, amaze, and so forth.), expressive body activities, and the evaluation of circumstances and settings.

Look into on feeling has expanded fundamentally in the course of recent decades with many fields contributing including brain research, neuroscience, endocrinology, solution, history, humanism, and considerably software engineering. The various speculations that endeavor to clarify the inception, neurobiology, experience, and capacity of feelings have just encouraged more extraordinary research on this point. Ebb and flow ranges of research in the idea of feeling incorporate the improvement of materials that invigorate and evoke feeling. What's more, PET outputs and fMRI filters help concentrate the full of feeling procedures in the mind.

\section{Definitions, and separation}

"Emotion" goes back to 1579, when it was adjusted from the French word émouvoir, which signifies "to mix up". The term feeling was acquainted into scholarly dialog with supplant energy. As per one lexicon, the most punctual forerunners of the word likely goes back to the very inceptions of dialect. The cutting edge word feeling is heterogeneous in a few employments of the word, feelings are serious sentiments that are coordinated at somebody or something. Then again, feeling can be utilized to allude to states that are mellow (as in irritated or content) and to states that are not coordinated at anything (as in nervousness and misery). One line of research subsequently takes a gander at the importance of the word feeling in regular dialect and this use is fairly not quite the same as that in scholarly talk. A different line of research gets some information about dialects other than English, and one fascinating finding is that numerous dialects have a comparable yet not indistinguishable term 
Feelings have been depicted by a few scholars as discrete and predictable reactions to inner or outside occasions which have a specific criticalness for the living being. Feelings are brief in span and comprise of an organized arrangement of reactions, which may incorporate verbal, physiological, behavioural, and neural systems. Psychotherapist Michael C. Graham depicts all feelings as existing on a continuum of power. Consequently, dread may extend from gentle worry to fear or disgrace may go from basic humiliation to dangerous disgrace. Feelings have additionally been portrayed as organically given and a consequence of advancement since they gave great answers for old and repeating issues that confronted our precursors. Temperaments are sentiments that have a tendency to be less exceptional than feelings and that regularly do not have a logical jolt.

Feeling can be separated from various comparative builds inside the field of full of feeling neuroscience:

- Feelings are best comprehended as a subjective portrayal of feelings, private to the individual encountering them.

- Moods are diffuse full of feeling states that for the most part keep going for any longer terms than feelings and are likewise normally less extraordinary than feelings.

- Affect is an including term, used to portray the points of feeling, sentiments, and mind-sets together, despite the fact that it is generally utilized reciprocally with feeling. Furthermore, connections exist between feelings, for example, having positive or negative impacts, with direct alternate extremes existing. These ideas are portrayed in differentiating and order of feelings. Graham separates feelings as useful or useless and contends every single practical feeling have benefits.

\section{Five Types of Emotion}

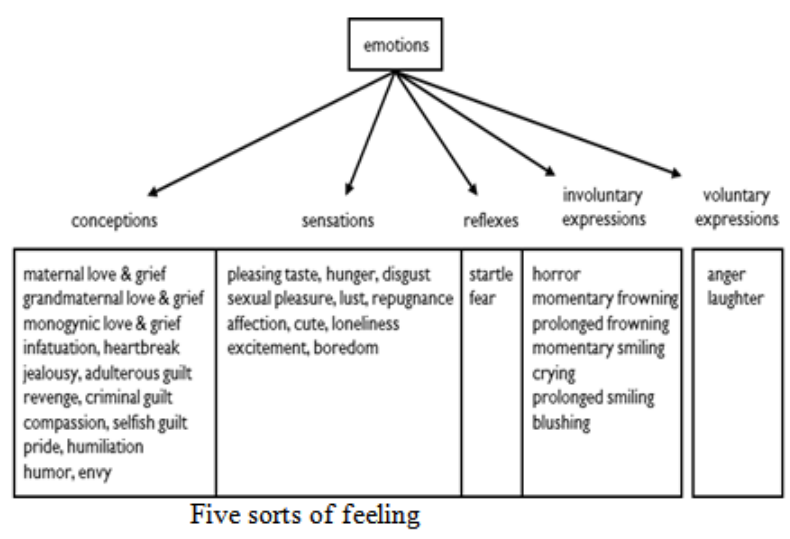

There square measure 5 sorts of feeling: originations, sensations, reflexes, automatic expressions and wilful expressions. Originations, sensations, reflexes and automatic expressions square measure organic expansions. They're transmitted to back to back era through copy. They're general to the species. Voluntary expressions square measure cultural diversifications. They're transmitted to consecutive generation through interaction. They vary by culture.Apprehension direct your behaviour. Apprehension square measure positive or negative mental effects that square measure triggered by conclusions.Maternal love could be a positive impact triggered by the conclusion "my kid is happy". Maternal grief could be a negative impact triggered by the conclusion "my kid is dead".A few apprehensions do trigger involuntary expressions that have a special purpose.Sensations direct your behaviour.Sensations square measure positive or negative mental affects that square measure triggered by the presence or absence of sensory stimuli.Pleasing style could be a positive impact triggered by the style of food. Hunger could be a negative impact triggered by the absence of food. Disgust could be a negative impact triggered by the smell of poisons, like faecal matter.Sensations will be triggered by stimuli that are real, recorded, remembered or notional. Men feel pleasure once they see an unadorned lady whether or not she is real, recorded, remembered or notional.Sensations trigger virtually no physical effects. A couple of sensations do trigger minorPhysical effects, like sacrament. However, sensations don't trigger any major physical effects, like augmented vital sign. Sensations don't have to trigger physical effects to direct your behaviour.A few sensations do trigger involuntary expressions that have a special purpose.Reflexes help you 


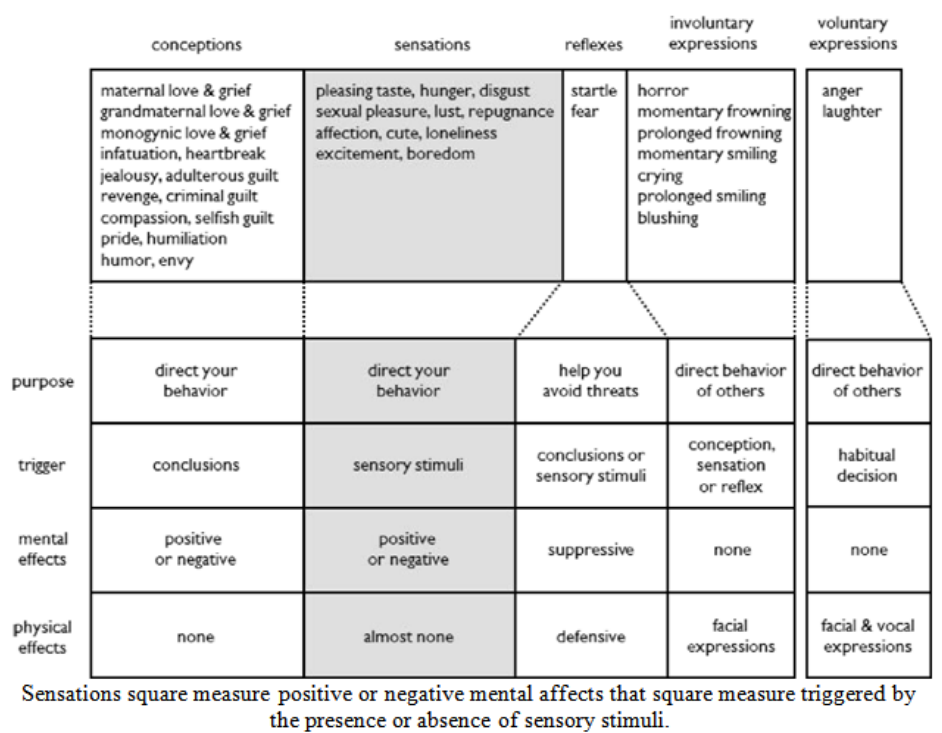

keep away from dangers. Reflexes square measure activated by conclusions or tactile boosts. Stress will beactivated by the determination "a man is illuminating a stacked firearm at me". Stress likewise can be

\begin{tabular}{|c|c|c|c|c|c|}
\hline & conceptions & sensations & reflexes & $\begin{array}{l}\text { involuntary } \\
\text { expressions }\end{array}$ & $\begin{array}{l}\text { voluntary } \\
\text { expressions }\end{array}$ \\
\hline & $\begin{array}{l}\text { maternal love \& grief } \\
\text { grandmaternal love \& grief } \\
\text { monogynic love \& grief } \\
\text { infatuation, heartbreak } \\
\text { jealousy, adulterous guilt } \\
\text { revenge, criminal guilt } \\
\text { compassion, selfish guilt } \\
\text { pride, humiliation } \\
\text { humor, envy }\end{array}$ & $\begin{array}{l}\text { pleasing taste, hunger, disgust } \\
\text { sexual pleasure, lust, repugnance } \\
\text { affection, cute, loneliness } \\
\text { excitement, boredom }\end{array}$ & $\begin{array}{l}\text { startle } \\
\text { fear }\end{array}$ & $\begin{array}{l}\text { horror } \\
\text { momentary frowning } \\
\text { prolonged frowning } \\
\text { momentary smiling } \\
\text { crying } \\
\text { prolonged smiling } \\
\text { blushing }\end{array}$ & $\begin{array}{l}\text { anger } \\
\text { laughter }\end{array}$ \\
\hline purpose & $\begin{array}{l}\text { direct your } \\
\text { behavior }\end{array}$ & $\begin{array}{l}\text { direct your } \\
\text { behavior }\end{array}$ & $\begin{array}{l}\text { help you } \\
\text { void threats }\end{array}$ & $\begin{array}{c}\text { direct behavior } \\
\text { of others }\end{array}$ & $\begin{array}{l}\text { direct behavior } \\
\text { of others }\end{array}$ \\
\hline trigger & conclusions & sensory stimuli & $\begin{array}{l}\text { nclusions or } \\
\text { nsory stimu }\end{array}$ & $\begin{array}{l}\text { conception, } \\
\text { sensation } \\
\text { or reflex }\end{array}$ & $\begin{array}{l}\text { habitual } \\
\text { decision }\end{array}$ \\
\hline $\begin{array}{l}\text { mental } \\
\text { effects }\end{array}$ & $\begin{array}{l}\text { positive } \\
\text { or negative }\end{array}$ & $\begin{array}{l}\text { positive } \\
\text { or negative }\end{array}$ & suppressive & none & none \\
\hline $\begin{array}{l}\text { physical } \\
\text { effects }\end{array}$ & none & almost none & defensive & $\begin{array}{c}\text { facial } \\
\text { expressions }\end{array}$ & $\begin{array}{l}\text { facial \& vocal } \\
\text { expressions }\end{array}$ \\
\hline
\end{tabular}

activated by seeing a snake. Reflexes trigger a mental effect that stifles originations and sensations. after you square measure panicked, you cannot feel delight or embarrassment. Concealment helps you consider maintaining a strategic distance from a danger by wiping out diversions. Reflexes trigger protective physical impacts. Startle automatically tenses neck muscles, hat counteract tearing by a predator's paws or claws. stress discharges Adrenalin to expand crucial sign, that battles or flight.

Reflexes square measure the sole feelings that trigger major physical impacts. Automatic expressions coordinate the conduct of others.Involuntary expressions square measure triggered by a conception, sensation or reflex. The reflex of worry triggers the involuntary expression of horror.Involuntary expressions have a special purpose than their trigger feeling. worry helps you avoid threats. The expression of horror on your face helps others avoid threats. 
Cultural difference in emotions

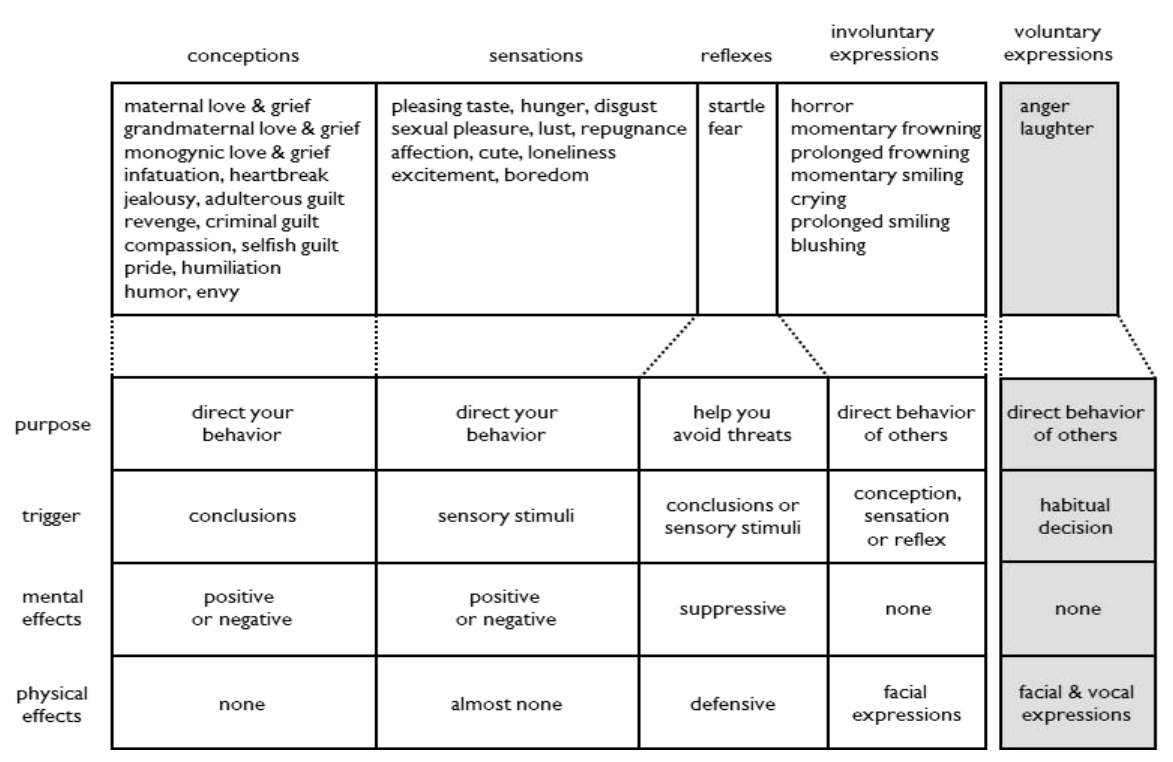

Voluntary expressions direct the behaviour of others.

Voluntary expressions square measure triggered by habitual call. Anger could be a habitual response to feeling revenge. Laughter could be a habitual response to feeling humour. These expressions appear involuntary as a result of they're deeply deep-seated habits, like walking or talking. Voluntary expressions square measure higher than speech. Anger is a lot of credible than sedately stating "I am being coerced by revenge to damage you". Laughter will be understood a lot of simply than associate audience of individuals at the same time speech "I feel humour".Emotions and cultureAccording to some theories, emotions are universal phenomena, albeit affected by culture. While some emotions are universal and are experienced in similar ways as a reaction to similar events across all cultures, other emotions show considerable cultural differences in their antecedent events, the way they are experienced, the reactions they provoke and the way they are perceived by the surrounding society. According to other theories, termed social constructionist, emotions are more deeply culturally influenced. The components of emotions are universal, but the patterns are social constructions. Some also theorize that culture is affected by emotions of the people.

\section{Social investigations of feelings}

Examine on the connection amongst culture and feelings goes back to 1872 when Darwin contended that feelings and the outflow of feelings are all inclusive. Since that time, the comprehensiveness of the six essential feelings (i.e., joy, misery, outrage, dread, sicken, and astound) has touched off an exchange among clinicians, anthropologists, and sociologists. While feelings themselves are widespread marvels, they are constantly impacted by culture. How feelings are experienced, communicated, seen, and controlled differs as an element of socially standardizing conduct by the encompassing society. Consequently, one might say that culture is a fundamental structure for analysts to comprehend varieties in feelings. Culture influences each part of feelings. Recognizing which feelings are great or awful, when feelings are proper to be communicated, and even how they ought to be shown are altogether affected by culture. Significantly more imperatively, societies differentially influence feelings, implying that investigating social settings is vital to understanding feelings. Through joining sociological, anthropological, and mental research accounts it can be inferred that investigating feelings in various societies is exceptionally mind boggling and the ebb and flow writing is similarly as unpredictable, mirroring numerous perspectives and the speculation.

\section{Sexual orientation and passionate expressions}

It can entice to sum up while considering the contrasts between men, ladies, and the different routes in which they express their feelings; men and ladies from different societies have been appeared to acknowledge the generalization that ladies are more enthusiastic than men. Normally, this point of view on men is just held in instances of discrete feelings and their relating expressions, for example, bliss, dread, sicken, or pity. At the point when men encounter pride or outrage, nonetheless, the vast majority are considerably less liable to accept this generalization. Leaving sexual orientation generalizations unchallenged would have different potential results. The conviction that ladies are more enthusiastic than men addresses our comprehension of passionate reactivity and direction frameworks. Besides, this presumption can impactsly affect the way we collaborate with each other and our general public on the loose. Hence, a developing division of current brain science research is committed to the basic examination of these generalizations 
Numerous analysts have inferred that the watched passionate contrasts amongst men and ladies principally come from mingled sexual orientation parts, as opposed to science. Consequently, the scope of enthusiastic expression that specific populaces experience is based, in expansive part, on their way of life's desires for gentility and manliness.

Passionate Maturity

In brain research, development is the capacity to react to nature in a fitting way. This reaction is by and large adapted instead of intuitive. Development additionally includes monitoring the right time and place to carry on and knowing when to act, as per the conditions and the way of life of the general public one lives in. Grown-up advancement and development speculations incorporate the reason in life idea, in which development underscores an unmistakable perception of life's motivation, directedness, and purposefulness, which adds to the inclination that life is important.

The status of development is recognized by the move far from dependence on guardianship and the oversight of a grown-up in basic leadership acts. Development has diverse definitions crosswise over lawful, social, religious, political, sexual, enthusiastic, and scholarly settings. The age or qualities appointed for each of these settings are attached to socially huge pointers of autonomy that frequently fluctuate subsequently of social notions. The idea of mental development has suggestions crosswise over both legitimate and social settings, while a blend of political activism and logical confirmation proceed to reshape and qualify its definition. As a result of these elements, the thought and meaning of development and youthfulness is to some degree subjective.

way. For youth today, the relentlessly broadening time of "play" and tutoring going into the 21st century comes in light of the expanding unpredictability of our reality and its advancements, which too request an expanding multifaceted nature of expertise and additionally a more comprehensive arrangement of preimperative capacities. A hefty portion of the behavioral and passionate issues related with puberty may emerge as kids adapt to the expanded requests set on them, requests which have turned out to be progressively preoccupied from the work and desires of adulthood.

Every individual has an alternate level of enthusiastic development. It is something which you can reliably chip away at and enhance after some time. You can utilize the accompanying indications of enthusiastic development to gage your own particular level:

\section{Adaptability}

You can see every circumstance as one of a kind and you can adjust your style as needs be.

\section{Obligation}

You assume liability for your own particular life. You comprehend that your present conditions are an aftereffect of the choices you have taken up to now. When something turns out badly, you don't hurry to accuse others. You distinguish what you can do any other way whenever and build up an arrangement to actualize these progressions.

3. You comprehend that vision trumps learning

You realize that you don't need every one of the appropriate responses. For whatever length of time that you can distinguish the issue, you can envision an answer and research the most ideal approach to actualize that arrangement.

\section{Self-improvement}

Addressing the difficulties of tomorrow requires learning and improvement today. You want to learn and a hunger for information. Learning and advancement exercises frame a key some portion of your timetable.

\section{You look for option sees}

Realizing that the way things are done can simply be enhanced, you energetically search out the feelings and perspectives of others. You don't feel debilitated when individuals can't help contradicting you. In the event that you feel that their way is better, you are glad to keep running with it.

6. Non-judgemental

Assortment makes the world a more delightful place. Notwithstanding when you can't help contradicting individuals, you don't want to scrutinize them. Rather, you regard their entitlement to their convictions. 
7. Versatility

There will dependably be things that turn out badly. There will dependably be difficulties and real frustrations. While you may at first be somewhat disturbed, passionate development enables you to express your emotions, recognize the moves you can make, and proceed onward.

8. A quiet aura

It's difficult to be quiet $100 \%$ of the time however you can be capable try to avoid panicking more often than not.

9. Reasonable positive thinking

You are not bamboozled. You realize that achievement requires exertion and persistence. You do, however, have a hopeful demeanor whereby you trust you can adapt to whatever life tosses at you. You likewise trust that there are openings out there for you, so you search them out.

10. Congeniality

You are typically simple to coexist with and individuals feel good moving toward you. Building connections is never invented; it comes simple to you.

\section{Self-conviction}

You acknowledge when others acclaim or compliment you. It feels great when they support. In any case, you realize that there will dependably be individuals who dislike however you are positive about your identity and what you do. On the off chance that you trust that a strategy is ideal for you, you will do it, regardless of whether they favor or not.

\section{Cleverness}

You don't consider yourself excessively important. You can appreciate a decent giggle with companions and associates, notwithstanding when you are the aim of the joke.

One of the best impediments to enthusiastic development is an absence of fearlessness. In the event that you feel that you might need in fearlessness, look at Unbreakable certainty.

\section{REVIEW OF LITERATURE}

Fischer AH, Rodriguez Mosquera PM, van Vianen AE,\& Manstead AS. (2004)

Authors did a secondary analysis on a society dataset on gender variations in six emotions, collected in thirty-seven countries everywhere the planet. The aim was to check the generality of the gender-specific pattern found in studies with Western respondents, specifically that men report a lot of powerful emotions (e.g., anger), whereas ladies report a lot of overwhelmed emotions (e.g., sadness, fear). The authors expected the strength of those gender variations to depend upon women's standing and roles in their individual countries, as operationalized by the Gender management live (GEM; United Nations Development Programme Human Development Report 2002). Overall, the gender-specific pattern of girl's reportage to expertise and categorical a lot of overwhelmed emotions and men a lot of powerful emotions was replicated, and just some interactions with the GEM were found.

\section{Costa Jr., Paul; Terracciano, Antonio; \& McCrae, Robert R. (2001)}

The authors conducted test from 26 cultures suggest that gender differences are small relative to individual variation within genders; differences are replicated across cultures for both college-age and adult samples, and differences are broadly consistent with gender stereotypes: Women reported themselves to be higher in Neuroticism, Agreeableness, Warmth, and Openness to Feelings, whereas men were higher in Assertiveness and Openness to Ideas. Contrary to predictions from evolutionary theory, the magnitude of gender differences varied across cultures. Contrary to predictions from the social role model, gender differences were most pronounced in European and American cultures in which traditional sex roles are minimized. Possible explanations for this surprising finding are discussed, including the attribution of masculine and feminine behaviours to roles rather than traits in traditional cultures.

Kateri McRae, Kevin N. Ochsner, IrisB.Mauss, John J. D. Gabrieli, \& James J. Gross. (2008)

Despite strong popular apprehension of gender differences in emotionality and striking gender differences in the prevalence of disorders thought to involve emotion dysregulation, the literature on the neural bases of emotion regulation is nearly silent regarding gender differences the purpose of the present study was to address this gap in the literature. Using functional magnetic resonance imaging, we asked male and female participants to use a cognitive emotion regulation strategy (reappraisal) to down-regulate their emotional 
responses to negatively valanced pictures. Behaviourally, men and women evidenced comparable decreases in negative emotion experience. Neutrally, however, gender differences emerged. Compared with women, men showed (a) lesser increases in prefrontal regions that are associated with reappraisal, (b) greater decreases in the amygdala, which is associated with emotional responding, and (c) lesser engagement of ventral striatal regions, which are associated with reward processing. We consider two non-competing explanations for these differences. First, men may expend less effort when using cognitive regulation, perhaps due to greater use of automatic emotion regulation. Second, women may use positive emotions in the service of reappraising negative emotions to a greater degree. We then consider the implications of gender differences in emotion regulation for understanding gender differences in emotional processing in general, and gender differences in affective disorder.

Fujita, Frank; Diener, Ed; \& Sandvik, Ed. (1991)

Affect intensity (AI) may reconcile 2 seemingly paradoxical findings: Women report more negative affect than men but equal happiness as men. AI describes people's varying response intensity to identical and emotional stimuli. A college sample of 66 women and 34 men was assessed on both positive and negative affect using 4 measurement methods: self-report, peer report, daily report, and memory performance. A principalcomponents analysis revealed an affect balance component and an AI component. Multimeasure affect balance and AI scores were created, and $t$ tests were computed that showed women to be as happy as and more intense than men. Gender accounted for less than $1 \%$ of the variance in happiness but over $13 \%$ in AI. Thus, depression findings of more negative affect in women do not conflict with well-being findings of equal happiness across gender. Generally, women's more intense positive emotions balance their higher negative affect.

Kring, Ann M.; Gordon, Albert H. (1998)

Although previous studies of emotional responding have found that women are more emotionally expressive than men, it remains unclear whether men and women differ in other domains of emotional response. We assessed the expressive, experiential, and physiological emotional responses of men and women in 2 studies. In Study 1, undergraduates viewed emotional films. Compared with men, women were more expressive, did not differ in reports of experienced emotion, and demonstrated different patterns of skin conductance responding. In Study 2, undergraduate men and women viewed emotional films and completed self-report scales of expressivity, gender role characteristics, and family expressiveness. Results replicated those from Study 1, and gender role characteristics and family expressiveness moderated the relationship between sex and expressivity.John Brebner(2003) In two gatherings, one Australian, the other universal, sexual orientation contrasts in self-reports of the recurrence and force of as of late encountering eight feelings were surveyed by ttests, and impact sizes measured utilizing Cohen's d (Cohen, 1992). The eight feelings were Affection, Anger, Contentment, Fear, Guilt, Joy, Pride, and Sadness. In the Australian gathering measurably huge contrasts between the sexual orientations were found for the recurrence of Affection, Anger, Fear, Joy, and Sadness with females scoring higher. Guys scored higher on Pride. The main power contrasts for the Australian gathering were for Affection and Sadness where females scored higher, and Pride where guys scored higher. For the global example, critical sexual orientation contrasts for the recurrence of Affection, Anger, Contentment, Fear, Joy and Sadness were found with females scoring higher than guys. Sexual orientation contrasts in force were found for the greater part of the feelings aside from Pride, again with guys scoring higher than females. Communicated in standard deviation units, the greater part of the impact sizes are little, and some are amazingly little. The biggest impact size was $\mathrm{d}=0.30$ for Affection in the worldwide gatheringRichard P. Bagozzi, Nancy Wong\& Youjae Yi (1999)

An integrative clarification recommends that culture and sex cooperate to create in a general sense diverse examples of relationship amongst positive and negative feelings. Individuals in autonomous based societies (e.g. The United States) encounter feelings in oppositional (i.e. bipolar) ways, while individuals in reliant based societies (e.g. China) encounter feelings in argument ways. These examples are more grounded for ladies than men in both societies. In support of the hypothesis, Study 1 demonstrated that positive and negative feelings are unequivocally corresponded contrarily for American ladies and pitifully associated conversely for American men, however connected decidedly for Chinese ladies and feebly related decidedly for Chinese men. In Study 2, discoveries for Koreans, albeit blended, were nearer to the outcomes for Chinese.

Ritu Singh, Kusha Pant and Laitonjam Valentina (2013)did study to find out that there is a difference in emotional maturity components between males and females. The study showed that girls scored significantly higher on the social adequacy dimension of social maturity whereas boys were observed score higher on the social adjustment dimension of emotional maturity. However, no gender differences were observed on the composite social maturity and emotional maturity scores. Social and emotional maturity was found to be significantly positively correlated under both genders. Mukhtar Ahmad Wani1, Prof. Aejaz 
Scope of the study: We have this knowledge that there is difference in emotional maturity in males and females. But this study reveals that there is no significant difference when we take culture into consideration so the future scope of the study is to find out other important variable along with culture.

\section{Objectives}

1. To find out the difference in emotional maturity in males and females from north India.

2. To find out the difference in emotional maturity in male and females from east India.

3. To find out the difference in emotional maturity in male and female from west India.

4. To fibd out the difference in emotional maturity in male and female from south India.

Hypotheses:

1. There be no significant difference in males and females in emotional maturity from north India.

2. There be no significant difference in males and females in emotional maturity from east India.

3. There be no significant difference in males and females in emotional maturity from west India.

4. There be no significant difference in males and females in emotional maturity from south India.

\section{RESEARCH METHODOLOGY}

This study is designed as a non- experimental in nature, therefore an experimental quantitative approach will be used in order to test the hypothesis. Emotional maturity scale by Yashvir sigh was used. And based on the results and discussions, the hypothesis may be either rejected or accepted.

\section{Sampling}

For the proposed study, a sample of 80 young adults (20 from north Indian further10malesand 10 females, 20 south Indians 10 males and 10 females, 20 east Indians 10 males and 10females, 20 west Indians 10 males and 10 females) within an age group of $18-25$ will betaken. The convenient technique will be used to collect the data and sample will be takenfrom different parts on India (north, south, east and west).

Tools

Keeping in view of our variables to be measured, the aim and goals of the study, the nature of the sample and the ease of collecting data, appropriate instruments with satisfactory psychometric properties are selected. The scales which we are going to use here are:

1. Emotional maturity scale by Yashvir singh

\section{Statistical Techniques}

Keeping in view the objectives and hypotheses of the current study following statistical techniques were used to analyze the data:

- Independent Sample Student's 't-test'.

IV. RESULT AND DISCUSSION

TABLE 1.1

\begin{tabular}{|l|l|l|l|l|l|}
\hline \multicolumn{6}{|c|}{ Group Statistics } \\
\hline & gender & $\mathrm{N}$ & Mean & Std. Deviation & Std. Error Mean \\
\hline \multirow{2}{*}{ north } & male & 10 & 122.2000 & 35.93760 & 11.36447 \\
\cline { 2 - 6 } & female & 10 & 133.1000 & 30.51211 & 9.64878 \\
\hline
\end{tabular}

TABLE 1.2

\begin{tabular}{|c|c|c|c|c|c|}
\hline \multicolumn{6}{|c|}{ Independent Samples Test } \\
\hline & & \multicolumn{4}{|c|}{ t-test for Equality of Means } \\
\hline & & $\mathrm{t}$ & df & Sig. (2-tailed) & Mean Difference \\
\hline \multirow[t]{2}{*}{ north } & Equal variances assumed & -.731 & 18 & .474 & -10.90000 \\
\hline & Equal variances not assumed & -.731 & 17.538 & .474 & -10.90000 \\
\hline
\end{tabular}

The table number 2.1, 2.2 represent that the $\mathrm{p}$ value is $(\mathrm{P}=.131$ and .132$)$ which more than $0.05(\mathrm{P}>.05)$. Hence there is no any significant difference in emotional maturity in male and female with influence of culture. Hence, we accept the null hypotheses number 1 that there is no significant difference in emotional maturity in male and female with influence of culture in north India. 
TABLE 2.1

\begin{tabular}{|l|l|l|l|l|l|}
\hline \multicolumn{6}{|c|}{ Group Statistics } \\
\hline \multirow{2}{*}{ East } & gender & $\mathrm{N}$ & Mean & Std. Deviation & Std. Error Mean \\
\cline { 2 - 6 } & male & 10 & 153.6000 & 32.17729 & 10.17535 \\
\cline { 2 - 6 } & female & 10 & 129.2000 & 36.72057 & 11.61206 \\
\hline
\end{tabular}

TABLE 2.2

\begin{tabular}{|c|c|c|c|c|c|}
\hline \multicolumn{6}{|c|}{ Independent Samples Test } \\
\hline & & \multicolumn{4}{|c|}{ t-test for Equality of Means } \\
\hline & & $\mathrm{t}$ & df & Sig. (2-tailed) & Mean Difference \\
\hline \multirow[t]{2}{*}{ East } & Equal variances assumed & 1.580 & 18 & .131 & 24.40000 \\
\hline & Equal variances not assumed & 1.580 & 17.695 & .132 & 24.40000 \\
\hline
\end{tabular}

The table number $2.1,2.2$ represent that the $\mathrm{p}$ value is $(\mathrm{P}=.131$ and .132$)$ which more than 0.05 $(\mathrm{P}>$.05). Hence there is no any significant difference in emotional maturity in male and female with influence of culture. Hence, we accept the null hypotheses number 1 that there is no significant differencein emotional maturity in male and female with influence of culture east India.

TABLE 3.1

\begin{tabular}{|l|l|l|l|l|l|}
\hline \multicolumn{6}{|c|}{ Group Statistics } \\
\hline \multirow{2}{*}{ west } & gender & $\mathrm{N}$ & Mean & Std. Deviation & Std. Error Mean \\
\cline { 2 - 6 } & male & 10 & 120.1000 & 22.74716 & 7.19328 \\
\cline { 2 - 6 } & female & 10 & 131.9000 & 16.90135 & 5.34468 \\
\hline
\end{tabular}

TABLE 3.2

\begin{tabular}{|c|c|c|c|c|c|}
\hline \multicolumn{6}{|c|}{ Independent Samples Test } \\
\hline & & \multicolumn{4}{|c|}{ t-test for Equality of Means } \\
\hline & & $\mathrm{t}$ & df & Sig. (2-tailed) & Mean Difference \\
\hline \multirow[t]{2}{*}{ west } & Equal variances assumed & -1.317 & 18 & .204 & -11.80000 \\
\hline & Equal variances not assumed & -1.317 & 16.616 & .206 & -11.80000 \\
\hline
\end{tabular}

The table number 3.1, 3.2 represent that the $\mathrm{p}$ value is $(\mathrm{P}=.204$ and .206$)$ which more than 0.05 $(\mathrm{P}>$.05). Hence there is no any significant difference in emotional maturity in male and female with influence of culture. Hence, we accept the null hypotheses number 1 that there is no significant differencein emotional maturity in male and female with influence of culture in west India.

TABLE 4.1

\begin{tabular}{|l|l|l|l|l|l|}
\hline \multicolumn{6}{|l|}{ Group Statistics } \\
\hline \multirow{2}{*}{ south } & gender & N & Mean & Std. Deviation & Std. Error Mean \\
\cline { 2 - 6 } & male & 10 & 139.4000 & 18.85147 & 5.96136 \\
\cline { 2 - 6 } & female & 10 & 116.8000 & 26.02050 & 8.22841 \\
\hline
\end{tabular}

TABLE 4.2

\begin{tabular}{|c|c|c|c|c|c|}
\hline \multicolumn{6}{|c|}{ Independent Samples Test } \\
\hline & & \multicolumn{4}{|c|}{ t-test for Equality of Means } \\
\hline & & $\mathrm{t}$ & $\mathrm{df}$ & Sig. (2-tailed) & Mean Difference \\
\hline \multirow[t]{2}{*}{ south } & Equal variances assumed & 2.224 & 18 & .039 & 22.60000 \\
\hline & Equal variances not assumed & 2.224 & 16.407 & .040 & 22.60000 \\
\hline
\end{tabular}

The table number 3.1, 3.2 represent that the $\mathrm{p}$ value is $(\mathrm{P}=.039$ and .040$)$ which less than $0.05(\mathrm{P}>.05)$. Hence there is significant difference in emotional maturity in male and female with influence of culture. Hence, we do not accept the null hypotheses number 1 that there is significant difference in males and females of south India.

\section{v. DISCUSSION}

With this we came to know there is no real difference in emotional maturity in male and female with influence of culture because both the male and female are getting same opportunity and same treatment because of modernization and increase in educating the female child. The sample was only taken in India not outside of India. Here we have taken only Indian students in further we can conduct research on foreign students. 